\title{
Peningkatan Peran Guru Sekolah Dasar Pembina UKGS Dalam Pengobatan Darurat untuk Menghilangkan Rasa Sakit Gigi dan Mulut
}

Ryana Budi Purnama, Helmi Hirawan, Mutia Rochmawati, Pratiwi Nur Widyaningsih, Dian Noviyanti, Desi Rachmawati, Rakhmawati, Shahnaz Dwi Permata Putri, Minda Anita, Kunthi Isri Wulandari, Dani Intan Prabawati, Tirta Wardana*

\section{Jurusan Kedokteran Gigi, Fakultas Kedokteran, Universitas Jenderal Soedirman, Jl. Dr. Soeparno, Karangwangkal Gedung E,}

*E-mail: tirta.wardana@unsoed.ac.id

\begin{abstract}
Abstrak - Pentingnya memperhatikan dan menjaga kondisi kesehatan gigi dan mulut untuk meningkatkan kualitas hidup seseorang. Salah satu upaya yang dilakukan untuk menjaga kesehatan gigi dan mulut di lingkungan sekolah adalah dengan pembentukan UKGS (Usaha Kesehatan Gigi Sekolah). Pada kegiatan UKGS, guru memiliki peran dalam memberikan pengobatan darurat untuk menghilangkan rasa sakit. Pengobatan darurat yang dilakukan oleh guru di sekolah dapat dilakukan pada kasus-kasus seperti avulsi, tersedak, serta abses. Pengabdian masyarakat ini bertujuan meningkatkan peran Guru Sekolah Dasar melalui UKGS untuk menjaga dan meningkatkan kesehatan gigi dan mulut seluruh peserta didik pada SDN yang berada di kawasan Karangtengah Kecamatan Baturaden Purwokerto. Metode pelaksanaan yang dilakukan berdasarkan pengoptimalan potensi kader guru UKGS meliputi identifikasi sekolah dan peserta sasaran, pelaksanaan pre-test, pematangan, pembinaan, peningkatan kader guru Pembina UKGS. Pembinaan dan pelatihan telah dilakukan terhadap guru Pembina UKGS dalam menghadapi kondisi kedaruratan seperti abses, tersedak dan avelse. Kegiatan post-test dilakukan untuk menganalisis peningkatan wawasan Pembina UKGS ketika menghadapi kondisi penanganan kedaruratan sakit gigi dan mulut.

Hasil: Uji Wilcoxon asymp.sig. (2-tailed) untuk mengetahui nilai signifikansi pemahaman kondisi kedaruratan oleh pembinan dan kader UKGS. Hasil analisis statistik menunjukan peningkatan pegetahuan guru sebesar 0,001 (<0,05), nilai tersebut menunjukan bahwa terdapat pengaruh tingkat pengetahuan mengenai pengobatan darurat. Hasil yang diperoleh diuji dengan Wilcoxon Test didapatkan perbedaan bermakna (sig=0,001, $p<0,05$ ). Terdapat peningkatan hasil rerata nilai pre-test sebesar 76,92 dan post-test sebesar 97,85. Kesimpulan dari kegiatan pengabdian ini yaitu terdapat peningkatan pengetahuan mengenai pengobatan dan penanganan kedaruratan rasa sakit gigi dan mulut pada guru SD.
\end{abstract}

Kata Kunci — Guru, UKGS, Pengobatan darurat, Sakit Gigi dan Mulut

\begin{abstract}
The importance of paying attention to and maintaining teeth and mouth's health conditions improves one's quality of life. One of the efforts made to maintain dental and oral health in the school environment is by conducting UKGS (Usaha Kesehatan Gigi Sekolah). In UKGS activities, teachers have a role in providing emergency treatment to relieve pain. The emergency treatment administered by teachers in schools can perform in cases such as avulsions, choking, and abscesses. This community service aims to increase elementary school teachers' role through UKGS to maintain and improve all students' oral health at SDN in the Karangtengah area, Baturaden District, Purwokerto. The implementation method was basely on optimizing the potential of UKGS teacher cadres, including identifying target schools and participants, pre-test implementation, maturation, coaching, and enhancement of UKGS teacher cadres. Coaching and training have been carried out for UKGS supervisors for abscess, choking and avelse conditions. Post-test activities to gain insight into emergency medicine and relieve tooth and mouth pain. Result: Wilcoxon asymp test.sig.(2-tailed) to determine the significance value of understanding emergency conditions by UKGS coaches and cadres. The statistical analysis results are known to be $0.001(<0.05)$; this value indicates an influence on the level of knowledge about emergency medicine. The results showed increased knowledge of teacher with the Wilcoxon Test; there was a significant difference (sig $=0.001, p<0.05$ ). There was an increase in the average pre-test value of 76.92 and posttest of 97.85. This service activity concludes that there is an increase in knowledge about the treatment and handling of the emergency tooth and mouth pain in elementary school teachers.
\end{abstract}

Keywords - Teacher, UKGS, Emergency treatment, Oral and dental health, 


\section{PENDAHULUAN}

Salah satu penyakit yang menyerang manusia di semua usia dengan sifat progressive banyak ditemukan pada penyakit di daerah gigi dan mulut, sehingga semakin parah apabila tidak mendapatkan perawatan dengan cepat [1]. Rendahnya pengetahuan serta kesadaran membiasakan pola hidup sehat terutama pada kesehatan gigi dan mulut, mengindikasikan menjadi penyebab masalah kesehatan di usia sekolah. Hal tersebut mempengaruhi fungsi dan peran dari gigi dan mulut seperti fungsi bicara, rasa percaya diri, fungsi pengunyahan, karies gigi, kecacingan, kelainan ketajaman penglihatan dan gizi [2]. Oleh karena itu, penting membangun sikap dan perilaku rutin anak-anak untuk terus menjaga kesehatan gigi dan mulut melalui rutinitas menyikat gigi dan pemeriksaan secara berkala. Pendekatan melalui pendidikan, perilaku, motivasi, serta kesadaran menjaga kesehatan gigi dan mulut oleh Pembina UKGS memiliki dampak positif [3]. Pembentukan Usaha Kesehatan Gigi Sekolah (UKGS) merupakan upaya menjaga kesehatan di lingkungan sekolah serta antisipasi terhadap kondisi kedaruratan sebagai pertolongan pertama di lingkungan sekolah.

Peran utama UKGS sebagai salah satu unit yang di bentuk sebagai pelayanan kesehatan terhadap peserta didik di lingkungan sekolah haruslah didukung dengan upaya peningkatan SDM (Sumber daya manusia). Peningkatan kemampuan SDM melalui pelatihan ataupun pendampingan secara berkala untuk dapat meningkatkan kemampuan dalam penangangan dan pengelolaan UKGS perlu dilakukan. Pelatihan dan pendampingan untuk meningkatkan pengetahuan dan keterampilan pengelola UKGS sehingga dapat memberikan edukasi kesehatan yang baik terhadap siswa didik. Hal tersebut merupakan bentuk upaya kesehatan perorangan sebagai langkah kuratif untuk perawatan kesehatan gigi dan mulut. Lebih dari itu, mengingat peran sentral UKGS dimana anak-anak menghabiskan sebagian besar waktunya di sekolah, sehingga pengembangan lingkungan yang sehat dan adopsi perilaku kondusif untuk kesehatan yang layak bila dilakukan di sekolah [4].

UKGS di lingkungan sekolah dasar binaan Puskesmas mempunyai sasaran seluruh siswa sekolah dasar dengan kisaran umur 6-14 tahun. Program UKGS diharapkan dapat membebaskan siswa dari penyakit gigi dan mulut. Program UKGS merupakan kegiatan promotif, preventif, kuratif sederhana yang dilakukan kepada siswa sekolah dasar [5]. Pelaksanaan kegiatan UKGS melibatkan puskesmas, dokter gigi, perawat gigi, petugas UKGS, guru dan dokter kecil. Di UKGS, Guru memiliki peran yang sentral tidak hanya sebagai seorang pendidik dan penggerak UKGS di sekolah binaan, akan tetapi berperan serta sebagai agen pertolongan pertama dalam penanganan permasalahan kesehatan di sekolah.
Guru merupakan komponen promoter terbaik dalam kegiatan pendidikan, disebabkan memiliki hubungan yang baik dalam mendidik dan memotivasi siswa. Hal tersebut selaras dengan peran dari guru sesuai pada pasal 1 UU No. 14 tahun 2015. Peraturan tersebut menyatakan bahwa guru merupakan profesi pendidik dengan peran utama memberikan peningkatan kapasitas pengetahuan melalui organisasi dengan mendidik, mengajar, membimbing, mengarahkan, melatih, menilai, dan mengevaluasi peserta didik. Ditambah lagi, pada pasal 10 guru haruslah memiliki kompetensi pedagogik, kepribadian, kompetensional dan profesional [6]. Guru berperan dalam proses pembelajaran anak-anak, melalui peningkatan pemahaman mengenai pentingnya menjaga dan merawat kesehatan terutama pada kesehatan gigi dan mulut. Guru membantu siswa belajar melalui pelatihan, menjelaskan, konferensi, disiplin, menciptakan pengalaman dan menilai siswa [7]. Ditambah lagi, guru berperan serta membantu tenaga kesehatan dalam pengumpulan data/ screening serta sebagai rujukan pertama kedaruratan apabila menemukan murid dengan keluhan penyakit gigi dan mulut.

Kondisi kegawatdaruratan sering ditemukan pada UKGS di sekolah dasar, terutama pada kejadian sakit gigi dan mulut. Beberapa kasus yang paling sering dijumpai oleh guru Pembina UKGS pada kondisi kedaruratan sakit gigi dan mulut seperti avulse, tersedak serta gingivitis. Kejadian kedarutan tersebut harus segera diberikan pertolong pertama di UKGS sebelum dibawa ke fasilitas kesehatan seperti puskesmas. Hal tersebut penting untuk dapat mengurangi kesakitan serta peningkatan keparahan hingga mengancam nyawa apabila terlambat diberikan pertolongan pertama. Disamping itu, keterlambatan pertolongan pertama dapat mempengaruhi konsentrasi belajar siswa, sehingga guru Pembina UKGS dituntut dapat melakukan penanganan dengan cepat. Pemahaman dan peranan guru sangat penting sebagai langkah dalam rangka meningkatkan derajat kesehatan anak peserta didik. Melalui pengabdian masyarakat ini telah dilakukan sebuah upaya meningkatkan peranan guru dalam pengobatan darurat untuk mengurangi rasa sakit gigi dan mulut. Pendampingan dan pelatihan terhadap Pembina UKGS diharapkan dapat meningkatkan peran serta menjaga serta membantu dalam menghadapi kondisi kegawatdaruratan di sekolah. Ditambah lagi, pelatihan ini diharapkan menjadi salah satu penerapan dan pengembangan ilmu pengetahuan dalam upaya menjaga dan meningkatkan derajat kesehatan pada anak.

\section{METODOLOGI PELAKSANAAN}

Kegiatan pengabdian masyarakat melalui peningkatan peran guru sekolah dasar sebagai Pembina UKGS dalam upaya menghadapi kegawatdaruratan dapat dilihat pada alur gambar 1 . 
Alur kegiatan yang dilakukan dengan modifikasi dari tiap kegiatan dengan memberikan evaluasi baik berupa ujian tertulis ataupun ujian lisan terhadap guru mengenai peran dan pengetahuan dalam menghadapi kondisi kegawatdaruratan. Adapun tahapan yang dilakukan yaitu sebagai berikut:

\section{Identifikasi sekolah dan peserta sasaran}

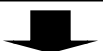

Pre test pemahaman kader dan inventarisasi UKGS

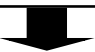

Pemberian materi kader UKGS

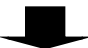

Pelatihan-suvervisi kader guru Pembina UKGS

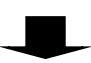

Pendampingan atau supervise Pembina UKGS

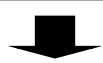

Monitoring dan evaluasi

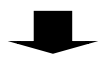

\section{Keberlanjutan}

Gambar 1. Alur pelaksanaan kegiatan

\section{Identifikasi sekolah dan peserta sasaran}

Kegiatan diawali dengan dengan beberapa tahapan seperti survey, sosialisasi, dan evaluasi pemahaman kader guru pembina UKGS. Tahapan pertama, Kami melakukan identifikasi mengenai kondisi kegawatdaruratan serta permasalahan kesehatan yang sering terjadi pada sekolah-sekolah dasar di desa binaan. Identifikasi ini dilakukan untuk menentukan pendampingan dan pembinaan yang tepat terhadap Pembina dan kader UKGS. Kegiatan pendampingan dan pembinaan guru Pembina dan kader UKGS melalui pelatihan, pemberian materi dan simulasi terhadap kondisi penanganan kegawatdaruratan yang terjadi, terutama pada kondisi daruratan yang sering dijumpai pada anak usia dini.

Pre-test pemahaman kader dan inventarisasi peralatan pendukung kegawatdaruratan UKGS

Pemahaman dasar pengelolaan serta penanganan kesakitan di UKGS merupakan hal penting dan mendasar yang wajib dikuasai oleh seorang guru sebagai Pembina dan kader UKGS. Hal tersebut yang mendorong kesadaran serta kemauan peserta didik dalam menjaga kesehatan. Hal tersebut tentulah harus diiringi dengan pemahaman yang cukup baik ketika kondisi kesehatan yang terganggu terjadi pada peserta didik.

Kegiatan diawali dengan pemberian pre test sebanyak 25 soal yang dilakukan secara daring dan luring untuk mengevaluasi pemahaman awal mitra UKGS mengenai abses, avulasi dan tersedak. Adapun pertanyan-pertanyaan pre-test yang diajukan terkait beberapa hal yaitu:

1. Penyebab tersedak, abses dan avulasi

2. Tanda-tanpa pada kejadian kegawatdaruratan

3. Bentuk perlakuan yang dilakukan pada kondisi kegawatdaruratan

4. Bentuk-bentuk tindakan yang harus dilakukan pada saat menemukan kondisi kedaruratan

5. Beberapa perlakuan yang dapat dilakukan jika menemukan beberapa kondisi permasalahan pada kesehatan gigi dan mulut seperti, bentuk pertolongan pertama, kedaruratan, hal-hal yang tidak boleh dilakukan apabila menemui kondisi tertentu, dan tatalaksana serta media yang dapat digunakan untuk penyimpanan gigi pada kondisi avulse

Analisis pre test dilakukan sebagai salah satu indikator penilaian untuk mengetahui pemahaman kader UKGS terhadap penanganan kondisi sebelum dilakukan pelatihan dan pendampingan. Analisis pre test berupa materi pengobatan darurat yang dilakukan untuk mendapatkan nilai rata-rata pemahaman dari Pembina dan kader UKGS.

Tahapan selanjutnya dilakukan inventarisasi peralatan penunjang pengobatan dalam kondisi kedaruratan. Inventarisasi dilakukan tidak hanya untuk mengetahui kesiapan dari UKGS. Namun, peralatan yang diinventarisasi digunakan untuk peralatan peraga dan pelatihan dalam proses pelatihan dan pendampingan. Kegiatan proses inventarisasi alat-alat kedokteran UKGS seperti diagnostik set, alat bahan sterilisasi alat seperti baskom, anios, alkohol, hand wash, hand sanitizer, masker, handscon, gelas kumur, polybag, kassa dan cotton ball dan roll. Beberapa alat peraga lainya untuk mendukung kegiatan pelatihan serta penunjang sebelum mendapatkan pelayanan kesehatan dari puskesmas dan rumah sakit seperti model gigi karies, model gigi sehat, poster, flip chart dan buku UKGS.

\section{Pelatihan-supervisi kader guru pembina UKGS}

Kegiatan pelatihan dilakukan secara daring selama masa pandemi COVID-19. Kegiatan pelatihan berfokus pada 3 materi yaitu abses, avulse dan tersedak. Ketiga materi yang disampaikan meliputi beberapa hal seperti kondisi pencegahan, penyebab terjadinya kegawatdaruratan, ciri-ciri kondisi kegawatdaruratan dan tindakan pertama yang harus dilakukan oleh Pembina dan kader UKGS pada saat menghadapi kondisi kegawatdarurtan. 
Supervisi dilakukan setelah kader pembina memperoleh penyuluhan serta pelatihan mengenai penanganan kondisi kedaruratan, serta pengobatan menghilangkan rasa sakit gigi dan mulut pada anak didik. Pembina kader diupayakan untuk dilakukan supervisi agar dapat meningkatkan derajat kesehatan gigi dan mulut khususnya pada anak didik yaitu murid sekolah dasar.

\section{Post test dan data analisis}

Pelaksanaan post test dilakukan untuk mengetahui sejauh mana pengetahuan para kader Pembina UKGS tentang pentingnya pengobatan darurat untuk menghilangkan rasa sakit gigi dan mulut pada anak-anak SD setelah dilakukan pembinaan. Penilaian dilakukan sebanyak 2 kali yaitu sebelum dan setelah dilakukan pelatihan. Penilaian dilakukan penilaian pada 2 indikator pengetahuan dan keterampilan dalam menganalisis, memberikan perawatan terhadap kondisi kedaruratan dan tatalaksana pasca pertolongan pertama.

Analisis data dilakukan dengan perhitungan nilai mean, median, uji normalitas dan analisis wilcoxon. Analisis wilcoxon dilakukan untuk mengetahui pengaruh tingkat pengetahuan mengenai pengobatan darurat sebelum dan setelah pendampingan serta pelatihan Pembina dan kader UKGS dalam menghadapi kondisi kegawatdaruratan sakit gigi dan mulut. Hasil analisis ditunjukan dengan nilai signifikansi $\mathrm{p}<0.05$ yang mengindikasikan bahwa terdapat pengaruh yang signifikan dari pelatihan yang diberikan.

\section{HASIL DAN PEMBAHASAN}

Tahapan survei di sekolah dan peserta sasaran dilakukan untuk mengetahui mengenai peran dan kegiatan UKGS di sekolah. Disamping itu, identifikasi ini dilakukan untuk melaksanakan perizinan dan sosialisasi terhadap rencana kegiatan yang akan dilaksanakan. Pemeriksaan fasilitas dari UKGS telah dilakukan untuk menilai bagaimana persiapan dari pelatihan dan kesiapan terhadap peran serta UKGS dalam menjaga keseharian peserta didik. Beberapa bahan yang digunakan untuk dapat membantu proses kegiatan berupa alat dan bahan sebagai upaya terhadap respon kedaruratan pada saat terjadi pada siswa didik dapat dilihat pada gambar 2 .

Proses kegiatan pelatihan yang dilakukan melalui 2 metode dengan pembentukan 2 tim, yaitu tim pemateri secara online serta tim pendampingan offline. Hal tersebut dilakukan sebagai upaya dalam mendukung program pemerintah mengurangi berkumpulnya orang dalam jumlah yang banyak, mengingat kegiatan dilakukan selama pandemi COVID-19. Namun, tim offline dalam jumlah terbatas tetap disediakan di sekolah untuk membantu mengarahkan kegiatan pelatihan dan pendampingan.
Kegiatan pendampingan, pemberian materi diawali dengan pemberian pre test untuk mengetahui pemahaman para kader UKGS sebelum diberikan pelatihan. Pre test berbentuk quisioner berbentuk google form serta lisan diberikan sebanyak 25 pertanyaan yang berhubungan dengan penangaan kondisi kedaruratan. Ditambah lagi, diakhir kegiatan pemberian post test sebagai indicator evaluasi tingkat keberhasilan pelatihan yang telah diberikan.

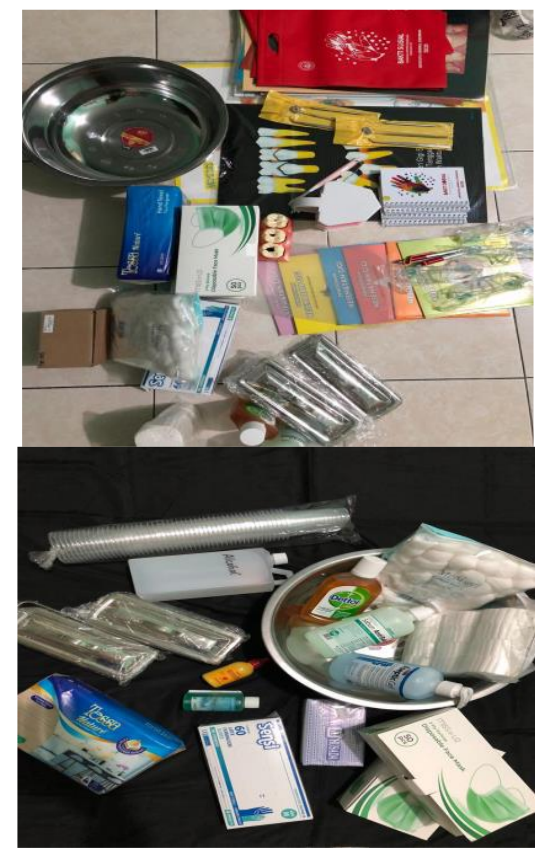

Gambar 2. Pengepakan dan inventaris fasilitas kesehatan UKGS

Materi pertama disampaikan mengenai beberapa kondisi dari kejadian kedaruratan pada sakit gigi dan mulut seperti abses, tersedak dan avlulse. Materi disampaikan berupa informasi mengenai ciriciri, tindakan pertama serta pengobatan yang dapat diberikan. Adapun kegiatan yang dilakukan melalui media zoom yang dapat dilihat pada gambar 3 .

Materi pertama yang diberikan yaitu mengenai penanganan pertama pada kondisi abses pada siswa didik. Kondisi abses pada anak usia dini terjadi diakibatkan dari infeksi odontogenik yang terdiri atas kumpulan pus atau nanah yang disebabkan akibat infeksi bakteri aerob dan anaerob [8]. Odotongenik merupakan salah satu infeksi yang terjadi pada rongga mulut yang disebabkan karies gigi yang menumpuk. Hal tersebut diindikasikan akibat kurangnya menjaga kesehatan gigi dan mulut salah satunya melalui sikat gigi. beberapa penyebab lainya kejadian abses dapat dikarenakan traumatic ataupun kegagalan pada saat perawatan saluran akar gigi [9]. Beberapa hal yang penting dipahami oleh pengelola UKGS mengenai ciri-ciri dari abses sehingga dapat memberikan penanganan yang tepat. Penanganan kondisi abses harus dilakukan dengan cepat 
dikarenakan dapat mempengaruhi jaringan sekitarnya apabila keterlambatan penanganan.

Beberapa gejala abses yang paling sering ditemui pada penderitanya seperti gigi yang mati, karies yang besar ataupun tambalan, nyeri konstan, gusi bengkak, kemerahan, nyeri saat ditelan, serta nanah yang keluar dari sela-sela gusi dan gigi. Pada kondisi lainya pada penderita dapat terjadi demam, pembengkakan getah bening di leher, lesu dan bahkan dapat menghilangkan nafsu makan. Salah satu tindakan yang harus dilakukan oleh pengelola UKGS pada saat menemukan kondisi kedaruratan yaitu secepat mungkin dibawa ke dokter gigi.

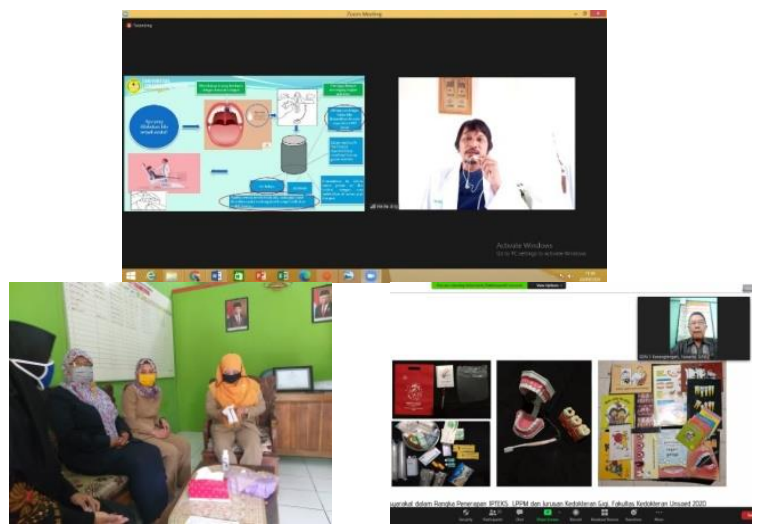

Gambar 3. Pemberian materi mengenai penanganan kedaruratan pada kesehatan gigi dan mulut

Pada kondisi kedaruratan terdapat beberapa langkah awal harus dilakukan untuk memberikan pertolongan pertama sehingga dapat mengurangi resiko yang lebih besar. Pengelola UKGS dapat memberikan perawatan terhadap peserta didik dengan berkumur menggunakan air garam hangat, pemberian kompres hangat pada area yang terkena abses yang sudah membesar, serta pencegahan dengan menyarankan rutinitas menyikat gigi 2 kali sehari perlahan dengan sakit gigi yang lembut.

Materi dan pendampingan yang kedua mengenai avulse atau dikenal sebagai trauma pada gigi. Trauma gigi seringkali terjadi pada usia dini terutama pada anak-anak usia sekolah berkisar 5-12 tahun yang disebabkan karena bermain, berlari, olahraga ataupun kecelakaan [10]. Trauma gigi seringkali terjadi pada gigi depan pada anak. Hal tersebut memberikan dampak pada fisik maupun psikis anak. Kondisi trauma gigi menyebabkan timbulnya rasa sakit, kesulitan mengunyah, maupun menelan, kesulitan mengucapkan huruf dengan jelas, dan juga menimbulkan rasa tidak percaya diri. Komplikasi yang disebabkan karena trauma gigi dapat menimbulkan berbagai dampak seperti nekrosis pulpa (kematian gigi), perubahan warna mahkota gigi (diskolorasi mahkota), fistula, periodontitis apikalis, maupun resorpsi akar eksterna [11].
Materi dan pendampingan penanganan kedaruratan selanjutnya yaitu pada kondisi tersedak. Kondisi tersedak merupakan kejadian yang disebabkan adanya benda asing yang menyumbat dan menghalangi aliran udara yang menyebabkan sulitnya untuk bernafas [12]. Kondisi tersedak merupakan kedaruratan yang paling sering terjadi pada anak usia dini, terutama pada balita (usia 1-2 tahun) dan anak (usia 2-12 tahun) yang sangat memerlukan penanganan yang cepat. Keterlambatan penanganan terhadap korban dapat berdampak terhadap kesulitan bernafas dan kekurangan oksigen bahkan menyebabkan kematian [13]. Kondisi tersedak disebabkan kondisi saluran nafas tersumbat oleh benda asing, dapat berupa makanan, mainan dan lain-lain [14]. Kondisi penderita tersedak biasanya ditandai dengan penderita memegang tenggorokan menggunakan kedua tangan korban, ketidakmampuan berbicara atau bernafas, batuk tanpa suara, kulit serta bibir dan kuku menjadi biru dan kehitamam, bahkan kehilangan kesadaran.

Keterlambatan penanganan kondisi tersedak bahkan dapat menyebabkan kematian. Oleh karena itu, pentingnya pertolongan pertama dengan cepat pada anak yang mengalami kondisi tersedak, sehingga perlu bagi para Pembina UKGS dapat memahami dan mengenali ciri dan penangananya. Penanganan dan tindakan yang cepat akan sangat mempengaruhi mempengaruhi keselamatan anak [15]. Beberapa tindakan pertolongan pertama yang dapat dilakukan yaitu:

1. Berikan lima tepukan punggung (back blows): berdiri di samping dan tepat di belakang korban satu tangan di letakan pada dada korban, dan condongkan tubuhnya ke depan. Berikan tepukan pada bagian punggung diantara kedua bahunya.

2. Berikan lima hentakan perut (abdominal thrusts): teknik respon pemberian tekanan paksa di daerah perut, hal tersebut dimaksudkan agar benda asing yang terdapat pada rongga pernapasan dapat keluar.

3. Teknik lima tepukan punggung dan lima hentakan perut bergantian: Teknik pertolongan pertama dengan melalui pemberian tepukan dibagian punggung dan perut sebanyak lima kali.

Teknik chest trust : teknik yang mirip dengan resusitasi jantung paru (RJP) atau cardiopulmonary resuscitation (CPR).

Tahapan evaluasi kegiatan diakhiri dengan pemberian post test terhadap peserta pelatihan. Adapun ringkasan hasil penilaian pre dan post test dapat dilihat pada tabel 1 . 
Tabel 1. Hasil penilaian pre dan post pelatihan

\begin{tabular}{|c|c|c|c|}
\hline \multirow{3}{*}{ Penilaian } & \multicolumn{3}{|c|}{$\%$ Penguasaan Peserta } \\
\hline & \multicolumn{2}{|c|}{ Pre test } & Post test \\
\hline & $\mathrm{B}$ & C K & B $\quad$ C $\quad \mathrm{K}$ \\
\hline \multicolumn{4}{|l|}{ Pengetahuan } \\
\hline $\begin{array}{l}\text { Mengenal ciri-ciri kondisi } \\
\text { kegawatdaruratan }\end{array}$ & B & & B \\
\hline $\begin{array}{l}\text { Teknik penanganan kondisi } \\
\text { kegawatdaruratan }\end{array}$ & & $\mathrm{C}$ & B \\
\hline $\begin{array}{l}\text { Penatalaksanaan pasca } \\
\text { penangan kegawatdaruratan }\end{array}$ & B & & B \\
\hline \multicolumn{4}{|l|}{ Keterampilan } \\
\hline $\begin{array}{l}\text { Pengenalan peralatan } \\
\text { pendukung penganan kondisi } \\
\text { kegawatdaruratan }\end{array}$ & B & & B \\
\hline $\begin{array}{l}\text { Teknik penanganan kondisi } \\
\text { kegawatdaruratan }\end{array}$ & & $\mathrm{C}$ & B \\
\hline $\begin{array}{l}\text { Penatalaksanaan pasca } \\
\text { penangan kegawatdaruratan }\end{array}$ & & $\mathrm{C}$ & B \\
\hline Nilai Terendah & & 56 & 88 \\
\hline Nilai Tertinggi & & 96 & 100 \\
\hline Rerata & & 77 & 98 \\
\hline
\end{tabular}

Catatan: B- baik, C-Cukup, K-Kurang

Analisis pre dan post test dilakukan dengan perhitungan nilai mean, median, uji normalitas dan uji wilcoxon untuk mengetahui efektivitas dan peningkatan pengetahuan dan kesiapan dari materi dan pendampingan yang telah diberikan dalam keadaan kegawatdaruratan. Uji analisis wilcoxon dilakukan untuk melihat dan mengetahui dampak pengaruh tingkat pengetahuan penanganan kedaruratan penanganan menghilangkan rasa sakit gigi dan mulut.

Hasil analisis secara statistik dilakukan untuk mengetahui dampak pelatihan yang diberikan dapat dilihat pada Tabel 2 .

Tabel 2. Analisis data pre dan post test pemberian materi dan pendamping Pembina kader UKGS.

\begin{tabular}{lccc}
\hline Kategori & Mean & Median & $\begin{array}{c}\text { Wilcoxon } \\
\text { significance }\end{array}$ \\
\hline Pre Test & 76.92 & 76.00 & $0.001^{*}$ \\
\hline Post Tex & 97.85 & 100.00 & \\
\hline *signifikan $p<0.05$ & &
\end{tabular}

*signifikan $p<0.05$

Hasil analisis nilai rata-rata pre-test materi pengobatan darurat sebesar 76.92 sedangkan nilai post test sebesar 97.85. Uji normalitas menggunakan uji Shapiro-wilk test dikarenakan sampel kurang dari 50. Analisis nilai post test dan pretest diketahui bahwa nilai uji normalisasi nilai signifikansi (p) pada kelompok posttest yaitu $0,000(\mathrm{p}<0,05)$, hal tersebut menunjukan data tidak terdistribusi normal, sebaliknya signifikansi (p) pada kelompok pretest sebesar 0,686 $(\mathrm{p}>0,05)$, nilai tersebut menyimpulkan bahwa data terdistribusi normal.
Uji homogenitas yang digunakan yaitu Levene test. Hasil analisis diketahui bahwa nilai signifikansi (p) pada kelompok pretest dengan nilai 0,140 $(\mathrm{p}>0,05)$, nilai tersebut menunjukan bahwa data dalam kelompok homogen. Nilai signifikansi (p) pada kelompok posttest sebesar $0,000 \quad(\mathrm{p}<0,05)$, nilai tersebut menunjukan bahwa data dalam kelompok tidak homogen. Data yang diperoleh berdasarkan hasil uji normalitas dan homogenitas didapat tidak terdistribusi normal dan tidak homogen sehingga dilakukan uji non parametrik menggunakan uji Wilcoxon. Hasil analisis data menggunakan uji statistik Wilcoxon asymp.sig. (2-tailed) dengan nilai sebesar $0,001(<0,05)$.

Nilai hasil analisis hubungan nilai pre dan post test menunjukan pengaruh tingkat pengetahuan para peserta Pembina UKGS dalam menghadapi keadaan kegawatdaruratan. Terdapat beberapa manfaat dari kegiatan pembinaan dan pelatihan yang diberikan. Meningkatnya pemahaman dari Pembina dan kader UKGS dapat meningkatkan derajat kesehatan gigi dan mulut pada anak-anak usia SD. Kesadaran dan pengetahuan mengenai pentingnya pengobatan darurat dengan pemberian pertolongan pertama yang tepat, diawali dengan pengenalan ciri yang specifik dapat menghilangkan rasa sakit gigi dan mulut pada siswa SD. Ditambah lagi, kegiatan ini menjadi salah satu kegiatan dalam mensukseskan program pemerintah dalam menggalangkan gerakan masyarakat hidup sehat untuk menjaga kesehatan gigi dan mulut.

Dari hasil evaluasi kegiatan dilakukan pengukuran 2 kategori yaitu pengetahuan dan keterampilan. Hasil menunjukkan terdapat peningkatan pengetahuan pembina atau kader UKGS terhadap pengobatan darurat untuk menghilangkan rasa sakit gigi dan mulut pada siswa SD.

\section{KESIMPULAN}

Dari kegiatan Pengabdian masyarakat yang telah dilakukan maka dapat disimpulkan bahwa peningkatan peran Guru Sekolah Dasar dalam pengelolaan UKGS dalam menghadapi kondisi kedaruratan pada sakit gigi dan mulut sesuai dengan target yang diharapkan. Dari kegiatan pengabdian ini diketahui bahwa terdapat peningkatan pengetahuan keterampilan Pembina dan kader UKGS melalui penanganan kondisi kedaruratan. Dari 25 peserta pelatihan yang berasal dari beberapa sekolah dasar yang terdapat di kawasan karangtengah kecaamatan baturaden mampu mengenali, memberikan dan melakukan tatalaksana pasca kondisi kedaruratan.

Saran pada kegiatan pengabdian ini yaitu dapat dilakukan evaluasi acara secara berkala pada Pembina dan kader UKGS yang telah diberikan pelatihan berupa materi untuk peningkatan pengetahuan mengenai penangaan dan pengobatan kondisi darurat untuk menghilangkan rasa sakit gigi dan mulut. 


\section{UCAPAN TERIMA KASIH}

Penulis mengucapkan terimakasih kepada LPPM UNSOED dalam membantu terlaksananya kegiatan pengabdian masyarakat melalui pendanaaan hibah pengabdian masyarakat tahun anggaran 2020.

\section{DAFTAR PUSTAKA}

[1] Kementerian Kesehatan RI, Rencana Aksi Nasional Pelayanan Kesehatan Gigi dan Mulut tang 2015-2019, Jakarta, 2015.

[2] A. Blaggana, Oral Health Knowledge, Attitudes and Practice Behaviour among Secondary School Children in Chandigarh, J. Clin. DIAGNOSTIC Res. (2016). Https://doi.org/10.7860/jcdr/2016/23640.8633.

[3] S.L. Jackson, W.F. Vann, J.B. Kotch, B.T. Pahel, J.Y. Lee, Impact of poor oral health on children's school attendance and performance, Am. J. Public Health. (2011). Https://doi.org/10.2105/AJPH.2010.200915.

[4] Kemenkes RI, Promosi Kesehatan di Sekolah, 2008.

[5] A. Faktor-Faktor Yang Mempengaruhi Kinerja Perawat Gigi, N. Ningrum, L. Widagdo, S. Patria Jati, D. Jurusan Keperawatan Gigi Poltekkes Kemenkes Bandung, D. Promosi Kesehatan, Analisis Faktor-Faktor Yang Mempengaruhi Kinerja Perawat Gigi Dalam Pelaksanaan Kegiatan UKGS (Usaha Kesehatan Gigi Sekolah) Di Puskesmas Wilayah Dinas Kesehatan Kabupaten Bandung, J. Kesehat. Gigi. (2015).

[6] Ana Riolina, Peran Guru dalam Meningkatkan Kesehatan Gigi dan Mulut Siswa di Sekolah Dasar, J. Ilmu Kedokt. Gigi. (2017).

[7] N. Abdullah, Hubungan Status Kesehatan Gigi Dan Mulut Anak Sekolah Dengan Pelaksanaan UKSG (Usaha Kesehatan Gigi Sekolah) Di
Sekolah Dasar dan Sederajat Se Kota Makassar, J. Media Kesehat. Gigi. (2018).

[8] Shweta, S.K. Prakash, Dental abscess: A microbiological review., Dent. Res. J. (Isfahan). (2013).

[9] M. Al-Malik, M. Al-Sarheed, Pattern of management of oro-facial infection in children: A retrospective, Saudi J. Biol. Sci. (2017).

Https://doi.org/10.1016/j.sjbs.2016.03.004.

[10] S. Sharma, R. Dua, Prevalence, causes, and correlates of traumatic dental injuries among seven-to-twelve-year-old school children in Dera Bassi, Contemp. Clin. Dent. (2012). Https://doi.org/10.4103/0976-237x.94544.

[11] D. Ram, O.N. Cohenca, Therapeutic protocols for avulsed permanent teeth: Review and clinical update, Pediatr. Dent. (2004).

[12] H. Suwardianto, . E., PELATIHAN Penangganan Korban Tersedak Terhadap Pemahaman Tujuan, Prosedur, Kewaspadaan, Dan Evaluasi Tindakan, J. Penelit. Keperawatan. https://doi.org/10.32660/jurnal.v4i2.328.

[13] P. Wulandini, E.M. Sari, A. Fitri, Perilaku Ibu Dalam Pertolongan Pertama Saat Tersedak Pada Anak Usia Toddler Di Posyandu Harapan Ibu Desa Penghidupan Tahun 2018, J. Keperawatan Abdurrab. (2018). https://doi.org/10.36341/jka.v2i1.499.

[14] K.B. Kirschman, G.A. Smith, Resale of recalled children's products online: An examination of the world's largest yard sale, Inj. Prev. (2007). https://doi.org/10.1136/ip.2006.013102.

[15] S. Notoatmodjo, Promosi Kesehatan \& Ilmu Perilaku, 2012. 
Jati Emas (Jurnal Aplikasi Teknik dan Pengabdian Masyarakat) KESEHATAN \& KEDOKTERAN Vol. 5 No. 1 Maret 2021 - e. ISSN: 2550-0821 